\title{
JUVENILE NASOPHARYNGEAL ANGIOFIBROMA- FIVE YEARS STUDY IN A TERTIARY HOSPITAL OF KERALA
}

\author{
Suchit Roy B. R', Sindhu V. Nath², Susan James ${ }^{3}$
}

${ }^{1}$ Additional Professor, Department of ENT, Government Medical College, Kozhikode.

${ }^{2}$ Associate Professor, Department of ENT, Government Medical College, Thiruvananthapuram.

${ }^{3}$ Associate Professor, Department of ENT, Government Medical College, Thiruvananthapuram.

\section{ABSTRACT}

\section{BACKGROUND}

Juvenile Nasopharyngeal Angiofibroma (JNA) is a locally aggressive benign vascular tumour exclusively amongst adolescent males. General characteristics, management and outcomes of 22 patients of JNA who have taken treatment at a tertiary Hospital in Kerala between 2003 and till 2008 were studied and evaluated.

Aim and Objective - This is a partly retrospective and partly prospective study to determine general characteristics, management and outcomes amongst the local population of Southern part of Kerala.

\section{MATERIALS AND METHODS}

22 patients attending the OPD of Department of ENT of Government Hospital attached to a Medical College in Thiruvananthapuram between 2003 and till 2008 were evaluated respectively. Demographical data, clinical presentation, duration of symptoms, stage of disease, surgical approach and outcomes of these 22 patients were reviewed and collected from the medical record office of the Hospital.

\section{RESULTS}

All patients were males and their age varied from 13 - 31 years at first presentation with a mean age of 19.5 years. The highest incidence was noted in the age group of 16 to 20 years (50\%). Nasal obstruction and nasal bleeding were the main presenting symptoms, $75 \%$ and $83.83 \%$ respectively. CT scan and MRI were helpful in $86 \%$ of cases to demarcate the tumour and plan surgical approaches. Lateral rhinotomy was done in $45.83 \%$ and in $29.16 \%$ trans-palatal approach was used; 12 patients were subjected to embolisation prior to surgery. Surgery was the first line of treatment for all our patients. Recurrences were seen in $2 / 22(9.09 \%)$. No major complications encountered in the study.

\section{CONCLUSION}

Juvenile nasopharyngeal angiofibroma is a benign, highly vascular, locally aggressive tumour exclusively affecting adolescent males. Its common symptoms are nasal bleeding and nasal obstruction. Computerised tomography is a must to assess the extent of lesion and for planning of treatment. Preoperative embolisation and hypotensive anaesthesia has considerably helped to decrease blood loss. Surgery is the goal of standard in treatment.

\section{KEYWORDS}

Tumour, Angiofibroma, Juvenile, Adolescent, Nasopharynx, Chromaffin and Paraganglioma.

HOW TO CITE THIS ARTICLE: Roy SBR, Nath SV, James S. Juvenile nasopharyngeal angiofibroma- five years study in a tertiary hospital of Kerala. J. Evolution Med. Dent. Sci. 2017;6(7):554-558, DOI: 10.14260/Jemds/2017/118

\section{BACKGROUND}

Nasopharyngeal Angiofibroma in Adolescents (JNA) is a locally aggressive benign, non-encapsulated, locally invasive vascular tumour exclusively amongst adolescent males. It comprises of $0.5 \%$ of all head and neck tumours ${ }^{1}$ and is the most common benign tumour of nasopharynx. The commonest site of origin of this tumour is described as from the superior aspect of the sphenopalatine foramen, which is formed by the sphenoidal process of palatine bone and pterygoid process of the sphenoid bone. Age distribution of

Financial or Other, Competing Interest: None.

Submission 14-12-2016, Peer Review 08-01-2017,

Acceptance 13-01-2017, Published 23-01-2017.

Corresponding Author:

Dr. Suchit Roy B. R,

Additional Professor

Department of ENT,

Government Medical College,

Kozhikode.

E-mail: suchithroybr@hotmail.com

DOI: $10.14260 /$ jemds $/ 2017 / 118$

(c) (i) $\ominus$ this entity is between 14 and 25 years. 2 Several cases have been reported involving men over 25 years de novo and even amongst female. 3 Bleeding fibroma of adolescence, juvenile nasal fibroma, non-chromaffin paraganglioma of terminal branches of maxillary artery are the synonyms. 2 Common clinical presentation includes nasal obstruction, epistaxis and nasopharyngeal mass.4 Several studies showed a close relation between these angiomas and androgen receptor expression, suggesting these are androgen-dependent. This could explain why the prevalence is higher in males. ${ }^{5}$ Due to its locally aggressive nature, results in extension of the tumour expanding from the nose to fill the antrum later spreading to infra-temporal fossa, which in turn expands the cheek and at times invades the ethmoid and produce a frog face deformity. Diagnosis is usually made based on a careful clinical history and a detailed physical examination to describe the signs and symptoms, the morphology and epidemiology and the radiological findings. CT scan and MRI have led to major advances in the accurate diagnosis and treatment of angiofibromas. Advent of nasal endoscopy makes it possible to precisely remove the tumour without 
external scars in tumours without extra-nasal extensions. Extension into orbit and cranial cavity can also occur. Biopsies are not recommended because of the vascular and haemorrhagic nature of this tumour. Arteriography is done to assess the vascular supply in larger tumours and to make it possible to embolise these vascular lesions to reduce intraoperative bleeding. Endoscopy approach is the current cornerstone of management. Recurrence is well recorded in these tumours, although they are histologically benign. ${ }^{5}$ Recurrence has been reported to be $20 \%-42 \%$, although it may be higher with intracranial extension. The mainstay of treatment is surgical excision. The other modalities of treatment include radiotherapy and chemotherapy. The choice of surgical approach entirely depends upon the location of the tumour and experience of the surgeon. Types of surgical approach includes midfacial degloving, lateral rhinotomy and trans-palatine and recently endoscopic approach are widely used. The present study is to analyse the patients attending a tertiary hospital with angiofibroma.

\section{Aims of the Study}

To study the incidence, clinical features and clinical course of Juvenile Angiofibroma in patients attending tertiary Hospital of Thiruvananthapuram; to identify the relevant investigations necessary to make the diagnosis and plan treatment of juvenile nasopharyngeal angiofibroma and outline the application and advantage of various surgical procedures in each particular case of angiofibroma.

\section{MATERIALS AND METHODS \\ Study Setting}

Department of ENT, Medical College, Thiruvananthapuram.

\section{Study Subjects}

All patients with juvenile nasopharyngeal angiofibroma treated in the Department of ENT, Medical College, Thiruvananthapuram, during the period $2003-2008$.

\section{Study Design}

Descriptive study.

\section{Study Period}

2003 - 2008.

\section{Sample Size}

22.

\section{Data Collection Method}

Data is collected in accordance to the proforma. Retrospective data of patients treated during the period from June 2003 to May 2006 was collected from records (Retrospective). From June 2006 onwards, data was collected directly from patients (Prospective). Between June 2003 and May 2007, 22 patients who were admitted and treated in the Department of ENT, Medical College, Thiruvananthapuram were included in this study. The main facts known about the juvenile angiofibroma are presented here such as historical data, aetiology, pathogenesis, incidence of tumour with reference to age, sex and site of origin, mode of presentation, clinical findings, different types of investigations, different modalities of treatment, post-operative problems and also the followup. All patients were operated in this Institute. The lesions were staged according to Radkowski's staging system. In this study, all 22 cases were diagnosed as angiofibroma. Pre-operatively, CT scan was taken in all patients. MRI scan was taken in patients suspected to have intracranial involvement. Angiography was done in 13 patients. Embolisation was done in 12 patients. As two patients were operated twice within the study period, the total number of sample is taken as 24 . All the data was analysed using standard statistical methods.

\section{RESULTS}

Total number of patients included in the study were 22 over a period of 5 years from June 2003 to May 2008. The year-wise distribution of the patient's admission is shown in Table 1.

\begin{tabular}{|c|c|}
\hline Year & No. of Cases \\
\hline 2003 & 4 \\
\hline 2004 & 5 \\
\hline 2005 & 6 \\
\hline 2006 & 5 \\
\hline 2007 & 4 \\
\hline Total & $\mathbf{2 4}$ \\
\hline Table 1. Showing Year-Wise Distribution of Patients \\
(n=24) \\
\hline
\end{tabular}

Two patients had recurrence and hence had to be operated twice. So the total number of surgeries are counted as 24 (Table 1). One was operated in 2005 and re-operated in 2006, another patient in 2005 and 2007. All patients were males and their age varied from 13 - 31 years at first presentation with a mean age of 19.5 years. The highest incidence was noted in the age group of 16 to 20 years (50\%) (Table 2).

\begin{tabular}{|c|c|c|}
\hline Age & No. of Patients & Percentage \\
\hline $0-5$ & $\mathrm{Nil}$ & $\mathrm{Nil}$ \\
\hline $6-10$ & $\mathrm{Nil}$ & $\mathrm{Nil}$ \\
\hline $11-15$ & 5 & 20.83 \\
\hline $16-20$ & 12 & 50 \\
\hline $21-25$ & 3 & 12.5 \\
\hline $26-30$ & 3 & 12.5 \\
\hline$>30$ years & 1 & 4.16 \\
\hline \multicolumn{3}{|c|}{ Table 2. Showing Distribution of Patients according to } \\
their Age (n=24) \\
\hline
\end{tabular}

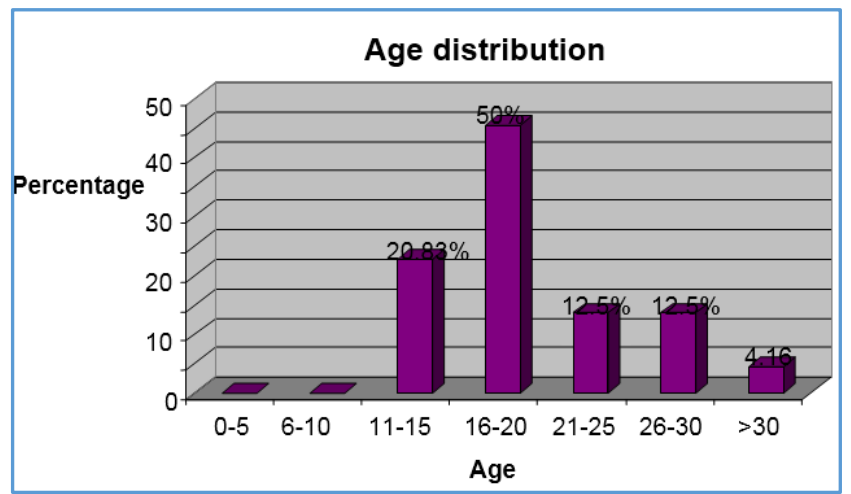

Figure 1. Showing the Age Distribution of the Patients $(n=24)$

$82 \%$ of the patients were aged below 25 years. But the occurrence of tumour in 4 patients above the age of 25 years 
shows that it does not regress after the age of 25 years or it may appear de novo in older patients.

\section{Presenting Symptoms}

Nasal obstruction and nasal bleeding were the main presenting symptoms; 2 patients had cheek swelling. Other symptoms included ear block, headache, change in voice, proptosis and altered sense of smell (Table 3).

\begin{tabular}{|c|c|c|}
\hline Presenting Symptom & No. of Patients & Percentage \\
\hline \multicolumn{3}{|l|}{ Nasal } \\
\hline Nasal obstruction & 18 & 75 \\
\hline Nasal bleeding & 20 & 83.33 \\
\hline Nasal mass & 2 & 8.33 \\
\hline Broadening of nose & 1 & 4.16 \\
\hline Altered sense of smell & 4 & 16.66 \\
\hline Headache & 5 & 20.83 \\
\hline Change in voice & 6 & 25 \\
\hline \multicolumn{3}{|l|}{ Aural } \\
\hline Ear block & 4 & 16.66 \\
\hline \multicolumn{3}{|l|}{ Face } \\
\hline Cheek swelling & 2 & 8.33 \\
\hline \multicolumn{3}{|l|}{ Eye } \\
\hline Proptosis & 1 & 4.16 \\
\hline Epiphora & - & - \\
\hline Decreased vision & - & - \\
\hline \multicolumn{3}{|c|}{$\begin{array}{l}\text { Table 3. Showing Presentation of Symptoms among the } \\
\text { Patients ( } n=24)\end{array}$} \\
\hline
\end{tabular}

In 18 patients, nasal obstruction was a major complaint, 10 had (R) sided and 8 had (L) sided complaints. Duration of this symptom varied from 1 month to 14 months. In 14 patients, the patients presented within 6 months (58.33\%), 9 patients between 6 and 12 months (37.5\%) (Table 4).

\begin{tabular}{|c|c|c|}
\hline Duration of Symptom & No. of Patients & Percentage \\
\hline$<6$ months & 14 & 58.33 \\
\hline $6-12$ months & 9 & 37.5 \\
\hline$>12$ months & 1 & 4.16 \\
\hline
\end{tabular}

Five patients gave history of previous surgery and one patient was treated with two surgeries and radiotherapy. These surgeries were performed outside this Institute. Duration between previous treatment and recurrence varied from 3 months to 6 years (Table 5).

\begin{tabular}{|l|c|}
\hline Surgery & 2 \\
Transpalatal & 1 \\
Transnasal & 1 \\
Lateral rhinotomy & 1 \\
Weber Ferguson & 1 \\
\hline \multicolumn{2}{|c|}{ Radiotherapy } \\
\hline \multicolumn{2}{|c|}{ Table 5. Showing Treatment Modalities in Patients with } \\
\hline
\end{tabular}

One patient had a transpalatal as well as lateral rhinotomy approach used in surgical treatment.

\section{Examination Findings}

On ARS (Anterior Rhinoscopy): presented with nasal mass in 13 patients, on PRS (Posterior Rhinoscopy): Nasopharyngeal mass was seen in 16 patients, Cheek swelling in 1 and Proptosis in 1 . All patients were investigated with routine haemogram and urine analysis. CT scan was taken in all patients and MRI was taken in 7 patients. These helped to find out the extent of the tumour, their intracranial extension and also helped in selection of surgical approach (Table 7).

\begin{tabular}{|c|c|}
\hline CT Scan Findings & 21 Patients \\
\hline Nasal cavity & 15 \\
\hline Nasopharynx & 22 \\
\hline Extra-Nasopharyngeal Extension & 12 \\
\hline Sphenoid & 4 \\
\hline Ethmoid & 4 \\
\hline Maxillary antrum & 10 \\
\hline Pterygopalatine fossa & 2 \\
\hline Infratemporal fossa & 0 \\
\hline Cheek and temporal fossa & 1 \\
\hline Orbit & 2 \\
\hline Intracranial extension & \\
\hline \multicolumn{2}{|c|}{ (nable 6. Showing } \\
\hline
\end{tabular}

In this study, the commonest extension of the tumour was to the sphenoid sinus. Two patients had intracranial extension, but there was no intradural involvement. Orbit was involved in one patient. His involved eye was blind due to cataract, which was a complication of prior radiotherapy. Depending on the CT scan findings, patients were staged according to Radkowski's staging system (1996).

\begin{tabular}{|c|c|c|c|}
\hline & & CT Scan & Percentage \\
\hline \multirow{2}{*}{ Stage I } & I A & 6 & 25 \\
\cline { 2 - 4 } & I B & 5 & 20.83 \\
\hline \multirow{3}{*}{ Stage II } & II A & 4 & 16.66 \\
\cline { 2 - 4 } & II B & 3 & 12.5 \\
\cline { 2 - 4 } & II C & 2 & 8.33 \\
\hline \multirow{2}{*}{ Stage III } & III A & 2 & 8.33 \\
\cline { 2 - 4 } & III B & 0 & 0 \\
\hline
\end{tabular}

Table 7. Showing the Staging of Tumour in Patients $(n=24)$

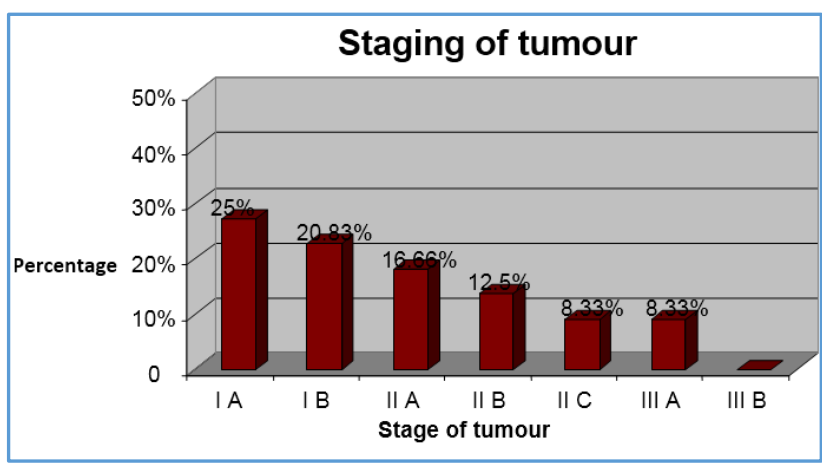

Figure 2. Showing the Staging of the Tumour in Patients ( $\mathrm{n}=24)$

$90 \%$ of patients were in stage I and II when presented to the Hospital on this study. 


\section{Treatment}

Angiography was done in 13 patients and preoperative Embolisation was done in 12 patients. One of the patients had tumour with blood supply from internal artery, hence Embolisation was not done. In others, the blood supply was from maxillary artery. Embolisation was done 24 - 48 hours prior to surgery. Bleeding was considerably less in patients who have undergone Embolisation. Most of the patients were treated surgically. Surgical approach depends on the size and extension of tumour.

\section{Hypotensive Anaesthesia}

This is the method we adopted to reduce the bleeding during the surgical removal of angiofibroma (Table 8).

\begin{tabular}{|c|c|c|}
\hline & No. of Patients & Percentage \\
\hline Transpalatal & 7 & 29.16 \\
\hline Transnasal & 2 & 8.33 \\
\hline Lateral rhinotomy & 11 & 45.83 \\
\hline Weber Fergusson & 2 & 8.33 \\
\hline Table 8. Showing Surgical approaches used in the Study \\
$(\mathbf{n = 2 4 )}$ \\
\hline
\end{tabular}

One of the patients who had undergone transpalatal surgery twice and lateral rhinotomy once, underwent radiotherapy later developed recurrence with orbital extension. He was treated with Weber Fergusson's approach and orbital exenteration. Another patient who had undergone transnasal surgery twice developed recurrence 15 months after the last surgery. He was treated with lateral rhinotomy and medial maxillectomy. One patient who had undergone transpalatal surgery developed recurrence 6 years later. He was treated with lateral rhinotomy and medial maxillectomy. Wilson's transpalatal approach was used for tumours confined to nasopharynx and paranasal sinuses. Commonest approach used in our study was Lateral Rhinotomy (50\%). The blood loss was less and was corrected with whole blood transfusion; 13 patients did not require any blood transfusion. There was no correlation between the age of the patient and vascularity of the tumour. Pre-operative Embolisation and use of Hypotensive anaesthesia helped to control the blood loss and also it provided a bloodless field for surgery. Nasal pack was removed after 24 - 48 hours.

\begin{tabular}{|c|c|}
\hline Synechiae & 3 \\
\hline Bleeding & 1 \\
\hline Palatal fistula & 1 \\
\hline Table 9. Showing the Post-Operative \\
Complications in the Study (n=24)
\end{tabular}

There was no major complication except one patient who developed haemorrhage, which was controlled with packing. One patient had palatal fistula, 3 had synechiae (Table 9).

\section{DISCUSSION}

Hippocrates in the 5th century BCE mentioned on juvenile nasopharyngeal angiofibroma in relation to nasal polyp. However, its association with puberty was identified by Chelius in 1847 and only in 1940 the term 'angiofibroma' was coined by Friedberg. ${ }^{2}$ Juvenile Nasopharyngeal Angiofibroma (JNA) is common amongst the adolescent males. In our study all patients were male with a mean age upon presentation being 15 years, which is similar to other published study. In this study of 22 cases, the peak incidence of the diseases was noticed between 16 - 20 years. The mean age was 19.5 years. Marti, ${ }^{6}$ Ehrlich and Abels (1948) reported a series of 29 cases with an average of 16 years. Benham $\mathrm{A}$ and others ${ }^{7}$ in reviewing 32 cases stated the most common age to be between 15 - 25 years. In our study also, around $60 \%$ patients were between 15 - 25 years; 4 patients were above age of 25 years. Atypical cases have been noted by Conley ${ }^{8}$ and Heagly (1968) who have recorded a 79-year-old male. All 22 patients were males, which goes in accordance with many studies. Wilson ${ }^{9}$ in 1972 mentioned 2 female cases, but later they were histologically suggested the final diagnosis of haemangioendothelioma for one and adenoid hypertrophy for the other. John Conley ${ }^{8}$ (1968) also observed angiofibroma in a female aged 57 years. The main complaints were nasal obstruction and epistaxis. The duration of symptoms varied from 1 month to 14 months. There was no correlation between duration of illness and extend of tumour. The cheek extensions are clinically apparent and are found to occur through the lateral wall of nasopharynx. After destroying the pterygoid plates, the tumour extends to pterygopalatine fossa winding around the posterior surface of maxilla through pterygopalatine fissure, thus entering the cheek. Martin ${ }^{6}$ described an alternate route to cheek by anterior extension of tumour to nasal fossa and then by transmaxillary extension to cheek destroying medial and antero-lateral walls of maxilla. In this study, all patients with lateral extension had destruction of pterygoid plates.

\begin{tabular}{|c|c|c|}
\hline Clinical Features & Apostle10 et al $^{10}$ & Present Study \\
\hline Nasal obstruction & $90 \%$ & $82 \%$ \\
\hline Nasal bleeding & $80 \%$ & $90.9 \%$ \\
\hline Cheek swelling & $30 \%$ & $9.1 \%$ \\
\hline
\end{tabular}

$16.66 \%$ patients $(4 / 24)$ gave history of previous treatment in this study. Time interval of recurrence varies from 3 months to 6 years. In 3 patients (12.5\%), the tumour was confined to nasopharynx and $86.4 \%$ have extra nasopharyngeal extension (Johns ${ }^{11}$ et al $82.5 \%$ ). Thus, the present study report and Johns ${ }^{11}$ et al (1986) are very similar in extra nasopharyngeal extension. Intracranial extension was found in $9 \%$ of cases. Johns et al have given a much higher incidence (30\%). Krekonien ${ }^{12}$ and Keto (1976) gave an incidence of $10 \%-20 \%$ intracranial extension, which favours the finding in our study. In this study, 5 patients presented with history of previous surgery or radiotherapy. Two patients in this series showed recurrence during the study period itself. Overall, recurrence rate is $22.7 \%$.

$\begin{array}{lll}\text { Incidence of Recurrence } & \\ \text { Gullane }^{2} \text { et al }(1992) & : & 30-40 \% \\ \text { Johns ME et al11 (1986) } & : & 24 \% \\ \text { English et al }{ }^{13} \text { (1972) } & : & 25-50 \% \\ \text { Present Study } & : & 22.7 \%\end{array}$

Spontaneous regression or sarcomatous change was not noted in our study. Batsakis ${ }^{14}$ in 1955 and Brener ${ }^{15}$ (1982) have reported sarcomatous change. Howard 16 (2001) postulated that timing of surgery, either during aggressive growth phase or latent phase of tumour, may be partially responsible for the local failure. He showed that $93 \%$ of 
recurrence occurred in patients with radiologic evidence of sphenoid diploe invasion through pterygoid canal. English ${ }^{13}$ quoted Harma in 1972 who indicated a 2-year interval after surgery without recurrence indicating cure. But in this study recurrence occurred even after 6 years. Hence, a longer followup is required to conclude as a cure. In suspected cases, CT/MRI is a must to diagnose early recurrence.

\section{CONCLUSION}

Juvenile nasopharyngeal angiofibroma is a benign, highly vascular, locally aggressive tumour, exclusively affecting adolescent males. Its common symptoms are nasal bleeding and nasal obstruction. Computerised tomography is a must to assess the extent of lesion and for planning of treatment. Preoperative embolisation and hypotensive anaesthesia has considerably helped to decrease blood loss. Surgery is the goal standard in treatment. No surgical approach fulfils all demands. Recurrence rate is found to be high in certain patients who need further study.

\section{REFERENCES}

[1] Paris J, Guelfucci B, Moulin G, et al. Diagnosis and treatment of juvenile nasopharyngeal angiofibroma. Eur Arch Otorhinolaryngol 2001;258(3):120-4.

[2] Gullane PJ, Davidson J, O'Dwyer T, et al. Juvenile angiofibroma: a review of the literature and a case series report. Laryngoscope 1992;102(8):928-33.

[3] Patrocinio JA, Patrocinio LG, Borba BHC, et al. Nasopharyngeal angiofibroma in an elderly woman. Am J Otolaryngol 2005;26(3):198-200.

[4] Tang IP, Sashinder S, Gopala KG, et al. Juvenile nasopharyngeal angiofibroma in a tertiary centre: ten-year experience. Singapore Med J 2009;50(3):261-4.
[5] Schick B, Rippel C, Brunner C, et al. Numerical sex chromosome aberrations in juvenile angiofibromas: genetic evidence for an androgen-dependant tumour? Oncol Rep 2003;10(5):1251-5.

[6] Martin H, Ehrlich HE, Abels JC. Juvenile nasopharyngeal angiofibroma. Annals of Surgery 1948;127(3):513-36.

[7] Beham A. Nasopharyngeal angiofibroma: an immuno histochmeical study of 32 cases. Virechows Arch A Pathol Anat Histopathol 1993;423:281-5.

[8] Conley J, Healy WV, Blaugrund SM, et al. Nasopharyngeal angiofibroma in juvenile. Surgery Gynecology \& Obstetrics 1968;126(4):825-37.

[9] Wilson WR, Miller D, Lee KJ, et al. Juvenile nasopharyngeal angiofibroma. Laryngoscope 1972;82(6):985-97.

[10] Apostol JV, Frazell EL. Juvenile nasopharyngeal angiofibroma. A clinical study. Cancer 1965;18(7):869-78.

[11] Johns ME, MacLeod RM, Cantrell RW. Estrogen receptors in nasopharyngeal angiofibromas. Laryngoscope 1980;90(4):628-34.

[12] Krekorian EA, Kato RH. Surgical management of nasopharyngeal angiofibroma with intracranial extension. Laryngoscope 1977;87(2):154-64.

[13] English GM, Hemenway WG, Cundy RL. Surgical treatment of invasiver angiofibroma. Archives of Otolaryngology 1972;96(4):312-8.

[14] Batsakis JG. Tumours of the head and neck. Baltimore: Williams and Wilkins 1987;4:174, 218.

[15] Bremer JW, Neel HB, DeSanto LW, et al. Angiofibroma: treatment trends in 150 patients during 40 years. Laryngoscope 1986;96(12):1321-9.

[16] Howard DJ, Lloyd G, Lund V, et al. Recurrence and its avoidance in juvenile angiofibroma. Laryngoscope 2001;111(9):1509-11. 